\title{
Towards A Modeling Framework of Social Contexts, Roles and Relations for Acquiring Role-specific Rules
}

\author{
Ya Wang ${ }^{1}$, Zhenzhen $\mathrm{Gu}^{1}$, Yuefei Sui ${ }^{1}$, Cungen Cao ${ }^{1}$ \\ ${ }^{1}$ Key Laboratory of Intelligent Information Processing, Institute of Computing Technology, \\ Chinese Academy of Sciences, Beijing 100190, China \\ \{wangya,yfsui,cgcao\}@ict.ac.cn; guzhenzhen@720@163.com
}

\begin{abstract}
Knowing the social roles of a person can help understand his or her interactions with the environment, and identification and acquisition of such social roles are very useful for a number of applications. In this paper, we propose a modeling framework of social contexts, roles and relations, and present a method of extracting role-specific rules from Web story episodes based on this framework. Then we introduce a rule expanding method which expands the seed rules of social roles. We believe that our work is useful for identifying social roles from text.
\end{abstract}

Keywords: Social Contexts and Roles, Commonsense Rules, Rule Expanding.

\section{Introduction}

A social role is a set of connected behaviors, rights, obligations, beliefs, expectations, and norms, as conceptualized by people in a social situation [1]. People behave based on their social roles. In real life, for instance, a physician does his best to cure diseases of patients. A mother protects her young children from harm. Thus knowing the social roles of people can help understand their interactions with the environment. In an intelligent storytelling system, the features of a character can be used to check the consistency of character behavior with respect to the role that the character plays [2]. In fact, identification of social roles is very helpful for a number of applications, e.g., targeted advertising, personalized recommendation and automatic story generation.

In this paper, we introduce a modeling framework of social contexts, roles and relations, and within such a framework, we discuss methods for acquiring role-specific rules. Nowadays, rules are still a common and powerful method of knowledge representation and reasoning. Many works have been done based on rules. [3] uses social rules to help recognize human activity. A business process is described using a set of business rules [4]. [5] develops rules for fault detection and identification. Some rule-based approaches are used for sentiment analysis [6][7].

This work is divided into two parts. First, we introduce a more efficient modeling framework to model social contexts, roles, and relations. Unlike other works (e.g. GFO [8]), we define social contexts, roles, and relations in such a way that role-specific rules are much easily uncovered and represented. Especially, we introduce some new 
notions, such as peripheral roles, context-free relation universals and contextualization, so that rules are much easily constructed from Web story episodes. Second, within the modeling framework, we use those rules as seeds, and design several heuristics to expand the seed rules.

There are a number of research works in the past decade, and they focus role identification in several situations. We roughly divide such applications into four broad categories. We believe that, with role-specific rules, such applications can become much easy.

The first category is social role identification in videos. [9] proposes a method for recognizing social roles from human event videos in a weakly supervised setting by using a Conditional Random Field (CRF) to model the inter-role interactions along with person specific unary features, such as gender and clothing. [10] presents an algorithm to recognize events in continuous video based on social roles of agents, which are inferred from their daily activities in the video. [11] introduces a method for determining the social roles of agents from their daily activities in long time-span surveillance video sequences, and the social roles of an agent are predicted with a Bayesian inference framework.

The second category is social role identification in audios. [12] focuses on automatic recognition of informal social roles in multiparty interactions. [13] proposes a method that combines the lexical choices made by people playing different roles and the social networks describing the interactions between the participants to recognize social roles in meetings automatically. [14] infers social roles in conversations of broadcast shows using information extracted from the speaking styles of the speakers and models the turn-taking behavior of the speakers with dynamic Bayesian network (DBN). [15] introduces a method to automatically detect the state of a meeting and the role of each participant in the meeting.

The third category of existing research works is social role identification in images. [16] proposes an approach to infer the same face across all images, as well as the social role (e.g. father, mother, or child) of each family member with a collection of family photos. [17] predicts human occupations in images by modeling the appearances of human clothing and surrounding context.

The final category of research works is social role identification on the Internet. [18] introduces a data mining model for social role discovery and attribution in Internet forums. [19] presents a data-driven method to discover social roles that exist in largescale online social systems. [20] builds a framework for detecting user occupations on microblogging platforms. [21] focuses on the prediction of the occupational class for Twitter users.

To the best of our knowledge, this paper is the first work to identify social roles from the perspective of commonsense rules. Unlike the above mentioned related works which usually identify roles in only one specific context, such as meeting and broadcast television show, we take various contexts into consideration.

The rest of this paper is organized as follows. In section 2, we discuss social contexts and roles, and section 3 focuses relations and relational roles. Section 4 presents the method of acquiring and expanding role-specific rules from Web story episodes. Section 5 concludes our work and presents the future work. 


\section{Modeling Social Contexts and Roles}

In our society, there are various social roles. Some roles are common, such as physician, student and father, while some roles are only well known to professional people, e.g. stage manager, log keeper and props manager in film-making. To facilitate the rolespecific rule acquisition for social roles, we need to develop a straightforward yet powerful framework.

Contexts define roles [8][22]. Different social contexts have their own social roles. A context has multiple social roles. For example, as displayed in Table 1, there are mother, father, daughter and son in a family; and there are brides, bridegrooms and so on at a wedding ceremony. So we acquire and categorize social roles based on contexts. So far, we have collected more than 300 social contexts [23], and have uncovered social roles in such contexts.

More formally, we view a social context as a social structure, in which there are some roles played by human beings. In this view, families, schools and hospitals are typical social contexts. Like GFO, we distinguish social contexts into social context universals and social context individuals, and thus Family, School and Hospital are referred to as social context universals; the family of some person is a social context individual. Nevertheless, when the context is clear, the paper uses social contexts and social context individuals interchangeably.

When a person plays a certain role in a social context individual, she or he is called the player of that role. A person can play multiple roles in a context individual. Two different persons can play the same social role. The structure of social roles can be descripted in Fig. 1 as shown below [8].

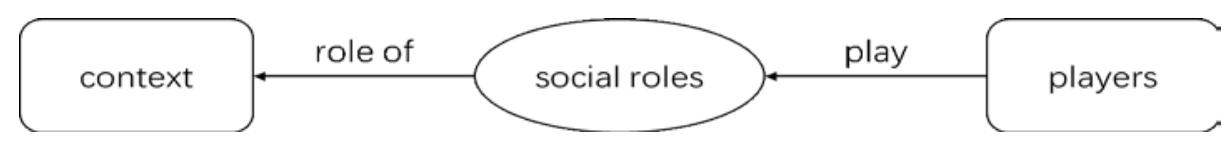

Fig. 1. Structure of social roles.

Two contexts are usually related by a person with two different base roles in the contexts. For example, in a family, a son is also a student of a middle school. So the family and the school is related by the person who plays both the role of son in the family and the role of student in the school.

As will be explained in detail in Section 3, where relational roles are introduced, we term the social roles in a social context as base roles. For example, Student is a base role in the social context School. Generally, a context has a few peripheral roles as shown in Table 1, which have a relation with the roles of the context or are excluded from the context by an event. For example, a hospital has roles of physician, patient, nurse and so on, and it also has patient's family members who have a kinship with the patient as peripheral roles. As another example, a school has roles of student, teacher and so on, and it also has retired teachers, who have retired from the school, as peripheral roles. 
Table 1. Five social contexts and their social roles.

\begin{tabular}{lll}
\hline Context & Base roles & Peripheral roles of context \\
\hline Hospital & physician, patient, nurse, pharmacist, ... & $\begin{array}{l}\text { patient's family, retired } \\
\text { physician, ... }\end{array}$ \\
School & student, teacher, principal, monitor, ... & $\begin{array}{l}\text { student's family, retired } \\
\text { teacher, ... }\end{array}$ \\
Restaurant & cook, diner, waiter, baker, cook assistant, ... & $\begin{array}{l}\text { employee's family, regular } \\
\text { guest, ... }\end{array}$ \\
Wedding & $\begin{array}{l}\text { bride, bridegroom, bridesmaid, groomsman, } \\
\text { Clower girl, ring bearer, ... }\end{array}$ & $\begin{array}{l}\text { bride's family, bridegroom's } \\
\text { family, ... }\end{array}$ \\
& $\begin{array}{l}\text { father, mother, son, daughter, wife, husband, } \\
\text { Frandmother, uncle, step-mother, step-father, } \\
\text { Family }\end{array}$ & $\begin{array}{l}\text { father-in-law, mother-in-law, } \\
\text { ex-wife, ex-husband, ... }\end{array}$ \\
\hline
\end{tabular}

A social context universal may have sub-context universals and part-context universals, and therefore all context universals together may form a hierarchy. For example, School can be classified as Elementary School, Middle School, High School and University, and all these contexts are sub-context universals of School. As another example, University can be divided into a number of part-context universals, such as University Library and University Classroom, as shown in Fig. 2. A sub-context universal has its own social roles. There are no professors and college students in Elementary School, but they occur in University.

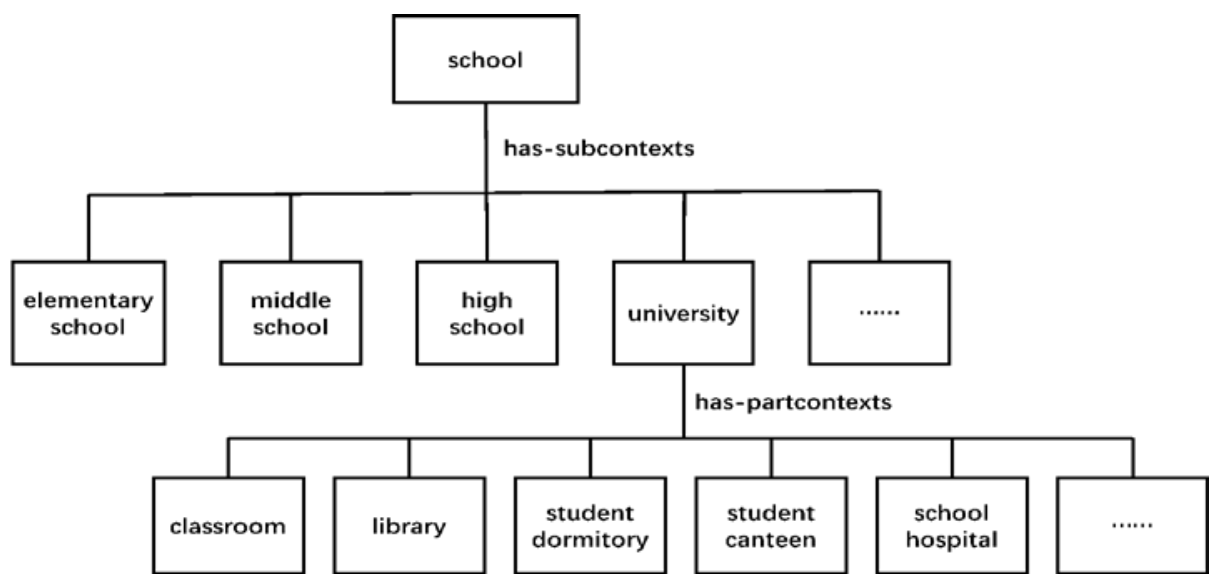

Fig. 2. Contexts, its sub-contexts, and part-contexts. 


\section{$3 \quad$ Modeling Relations and Relational Roles}

But things are more complicated when a treatment case occurs in a family. It could be that the daughter carelessly cuts her finger, and the mother treats the daughter, or that the mother carelessly cuts her finger, and the daughter treats the mother. In other words, we can not simply specialize treat(Treater, Treated) to treat(Parents, Child), let alone treat(Mother, Daughter).

To handle this situation, we introduce three notions, i.e. context-free relation universals, context-dependent relation universals and relational role universals. A context-free relation universal or a context-dependent relation universal relates a few relational role universals. For example, treat(Treater, Treated) is a context-free relation universal and operateOn(Treater, Treated) is a context-dependent relation universal, both with relational role universals, i.e. Treater and Treated.

For context-free relation universal, take the treat(Treater, Treated) as an example. treat(Treater, Treated) is a context-free relation universal, and when it is to be used in the context universal Hospital, it needs to be contextualized to Hospital to become treat(Attending Physician, Attended Patient). In other words, Treater is contextualized to Attending Physician, and Treated to Attended Patient. Here, the Attending Physician does not play the role of Treater, but is a contextualization of Treater instead as shown in Fig. 3. If there is a context-free relation universal and a specific context universal in the story episode, "her boyfriend is treating her grandmother in the hospital", we can identify that her boyfriend is the Attending Physician of her grandmother and her grandmother is the Attended Patient of her boyfriend. Thus, we can acquire the rolespecific rules with the information of context-free relation universals and context universals.

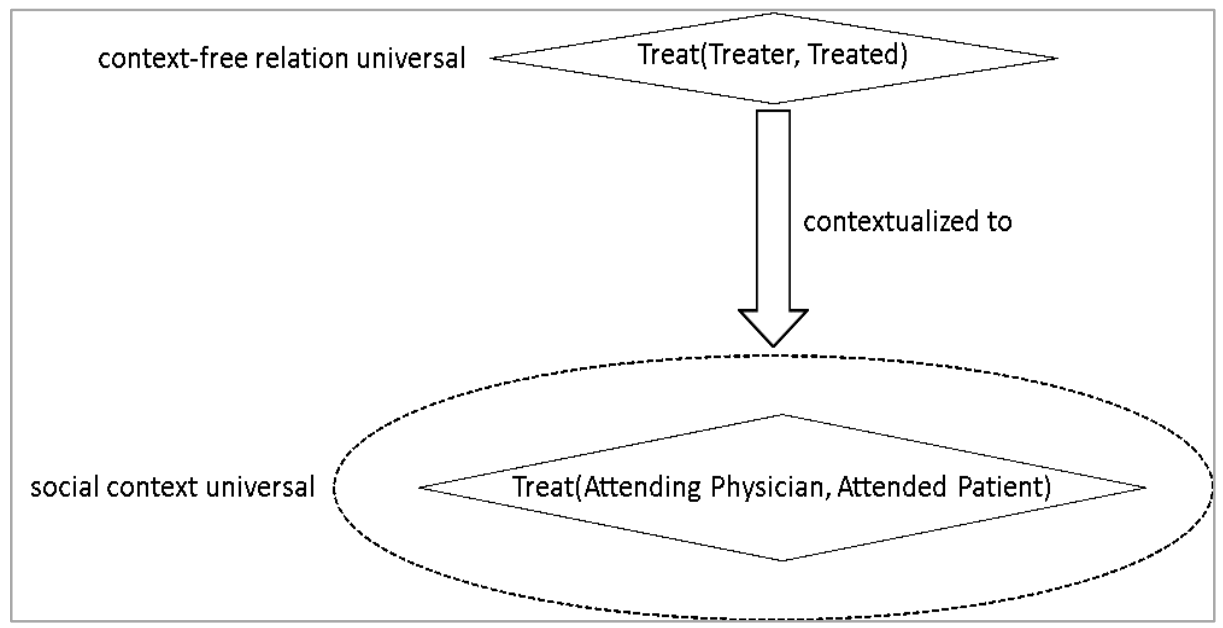

Fig. 3. Contextualization of context-free relation universal.

For the context-dependent relation universal, take the operateOn(Treater, Treated) for example. This relation universal usually exists in the context universal Hospital. 
Here, Treater plays the relational role Attending Physician and Treated plays the relational role Attended Patient as shown in Fig. 4. If the story episode contains a context-dependent relation universal, for example, "her boyfriend is operating on her grandmother", we can conclude that her boyfriend takes on the relational role of Attending Physician and her grandmother takes on the relational role of Attended Patient. Thus, we can acquire role-specific rules using the context-dependent relation universals according to our common sense.

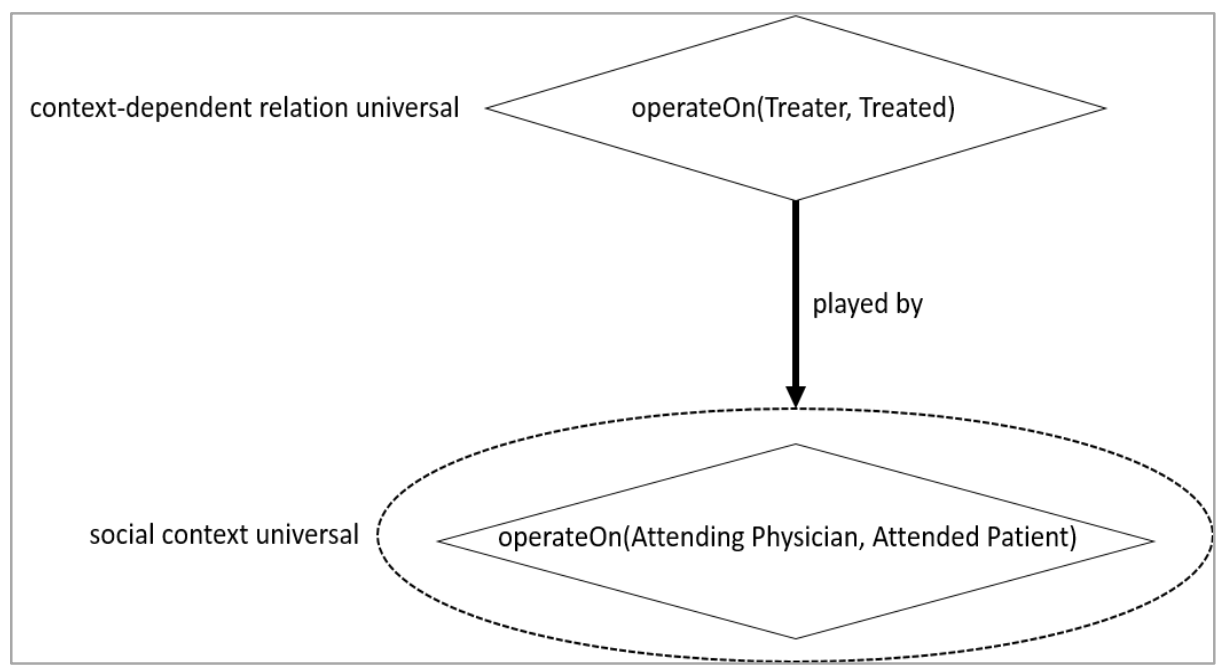

Fig. 4. Context-dependent relation universal "play”.

In the last five years, we have developed a separate framework - the Framework of Semantic Taxonomy of Description (FSTD), in which nearly 12,000 relation universals are designed in a frame-like manner [24].

We also need to introduce two other useful relation universals: hasRole(Person, Role) and hasRoleIn(Person, Role, Context) to relate a person, a role and a context. Literally, hasRole(Person, Role) means that the Person has the Role, and hasRoleIn(Person, Role, Context) means that the Person plays the Role in the Context. Again, note that the Role is a base role in the Context.

\section{$4 \quad$ Using the Modeling Framework to Acquire Role-specific Rules from Story Episodes}

Now, we focus on the role-specific rules. A role-specific rule represents an assertion of base roles in social contexts. More specifically, a role-specific rule can answer one of the following questions: Given a context, some of its roles, one or more persons, and an event:

1. under what conditions, persons play the right role(s)?

2. under what conditions, which relations are established or lost among the persons? 
3. What properties does each of the persons have, when we know the roles that they play?

4. who plays or loses which role(s), when the event happens?

5. what relations are established or lost among the persons, when the event happens?

6. What properties does each of the persons have, when the event happens?

7. Etc.

We acquire role-specific rules based on two phases: acquiring a set of seed rules from story episodes, and expanding the seed rules using a few heuristic dimensions of seed rules.

\subsection{Acquiring Seed Role-specific Rules from Story Episodes}

The burden on knowledge engineers is much high if we acquire commonsense rules through introspection. We believe that the Web provides a way for acquiring commonsense rules and speeds up commonsense rule acquisition. Thus, we first manually acquire commonsense rules according to the information from story episodes on the Web.

Roles are limited to represent the extrinsic features of an entity due to its participation in an event [25]. In a dynamic world, a variety of events occur all the time. Therefore, in order to acquire role-specific commonsense rules more effectively, we first extracted an initial Web corpus by using the combinations of an event and a context as keywords to invoke the search engine. Then we manually removed the results from the corpus that are either incomplete or difficult to understand, and also removed irrelevant contents such as digital ordinal strings or web identifiers in the corpus. Finally, we obtained the story episodes which are useful information for rule acquisition.

Table 2. Three story episodes captured from Web pages.

\begin{tabular}{lll}
\hline Story episodes & In Chinese & In English \\
\hline Episode 1 & $\begin{array}{l}\text { 我和老公结婚以后, 跟婆婆一 } \\
\text { 起住。 }\end{array}$ & $\begin{array}{l}\text { After I married to my husband, we lived } \\
\text { with my mother-in-law. }\end{array}$ \\
Episode 2 & $\begin{array}{l}\text { Mike在医院里工作很忙, 经常 } \\
\text { 给病人做手术到深夜。 }\end{array}$ & $\begin{array}{l}\text { Mike is busy with his work in a hospital } \\
\text { and often operates on the patient till late } \\
\text { in the night. }\end{array}$ \\
& $\begin{array}{l}\text { 那位年轻的女孩穿着婚纱, 站 } \\
\text { 在牧师身旁, 看上去十分漂 } \\
\text { 亮。 }\end{array}$ & $\begin{array}{l}\text { The young girl stood near the priest } \\
\text { in her wite wedding dress, and she } \\
\text { looked very beautiful }\end{array}$ \\
\hline
\end{tabular}

During acquiring commonsense rules from a story episode, we first need to know what social roles that a person plays in the episode. In a family, for example, a role that an individual plays is connected with other roles through kinship, marriage or adoption. We can identify these roles in a family through the relation between two different 
players (or participants) in the story episode. Some social roles are occupational roles such as physician, teacher, waiter, and cook. An occupational role conducts a professional action in exchange for payment. We can identify these occupational roles via role features (e.g. clothing and location). In the following, we present role-specific rules for each of the three story episodes without further explanation, for they are pretty straightforward.

Episode 1: After I married to my husband, we lived with my mother-in-law.

- Rule1.1: Person(p)\&Person(p')\&hasHusband(p, p')<-->hasWife(p', p)

- Rule1.2: Person(p)\&Person(p')\&hasHusband(p, $\left.\mathrm{p}^{\prime}\right)-->$ gender(p', male)

- Rule1.3: Person(p)\&Person(p')\&hasMother-in-law(p, p')\&gender(p, female)-->has Daughter-in-law(p', p)

- Rule1.4: Person(p)\&Person(p')\&hasMother-in-law(p, p')-->gender(p', female)

- Rule1.5: Person(p)\&Person(p')\&Person(p")\&hasDaughter-in-law(p, $\left.\mathrm{p}^{\prime}\right) \&$ hasWife $\left(p^{\prime \prime}, p^{\prime}\right)-->$ hasSon(p, p")

- Rule1.6: Person(p)\&Person(p')\&Person(p")\&hasDaughter-in-law(p, p')\&hasWife (p", p')--> hasMother(p", p)

Episode 2: Mike is busy with his work in a hospital, and often operates on patients till late in the night.

- Rule2.1: Person(p)\&Person(p')\&operateOn(p, p')--> $\exists d$ Physician(d)\&hasRole(p, d)

- Rule2.2: Person(p)\&Person(p')\&operateOn(p, $\left.\mathrm{p}^{\prime}\right)-->$ hasPatient(p, $\left.\mathrm{p}^{\prime}\right)$

- Rule2.3: Person(p)\&Person(p')\&operateOn(p, p')-->hasPhysician(p', p)

Episode 3: The young girl stood near the priest in her white wedding dress, and she looked very beautiful.

- Rule3.1: Person(p)\&Person(p')\&Priest(p")\&Wedding-Dress(w)\&wear(p, w)\&hasR ole(p', p")\&standNear(p, p')-->

The episodes and the rule acquisition above indicate that our framework is adequate as a role-specific commonsense acquisition technique. In the following section, we will show that the framework is also adequate for expanding the seed rules.

\subsection{Expanding the Role-specific Seed Rules}

The role-specific commonsense rules that we can acquire from Web pages are only a fraction of the rules that we actually possess in our brain. It is difficult to ensure the completeness of commonsense rules acquired through story episodes. In this section, based on the analytical framework introduced in section 3, we present a practical method to expand the acquired seed rules (ASRs). The method is based on dimension analysis of ASRs and a few heuristic techniques.

Through a comprehensive reflection on social roles, we find that, underlining each role, there are some associated pieces of evidence that not only highlight the role but 
also support the human judgements about the role, that we call dimensions of those roles. We summarize four dimensions for acquiring commonsense rules, namely, physiological dimension, psychological dimension, social dimension and physical dimension as shown in Fig. 5.

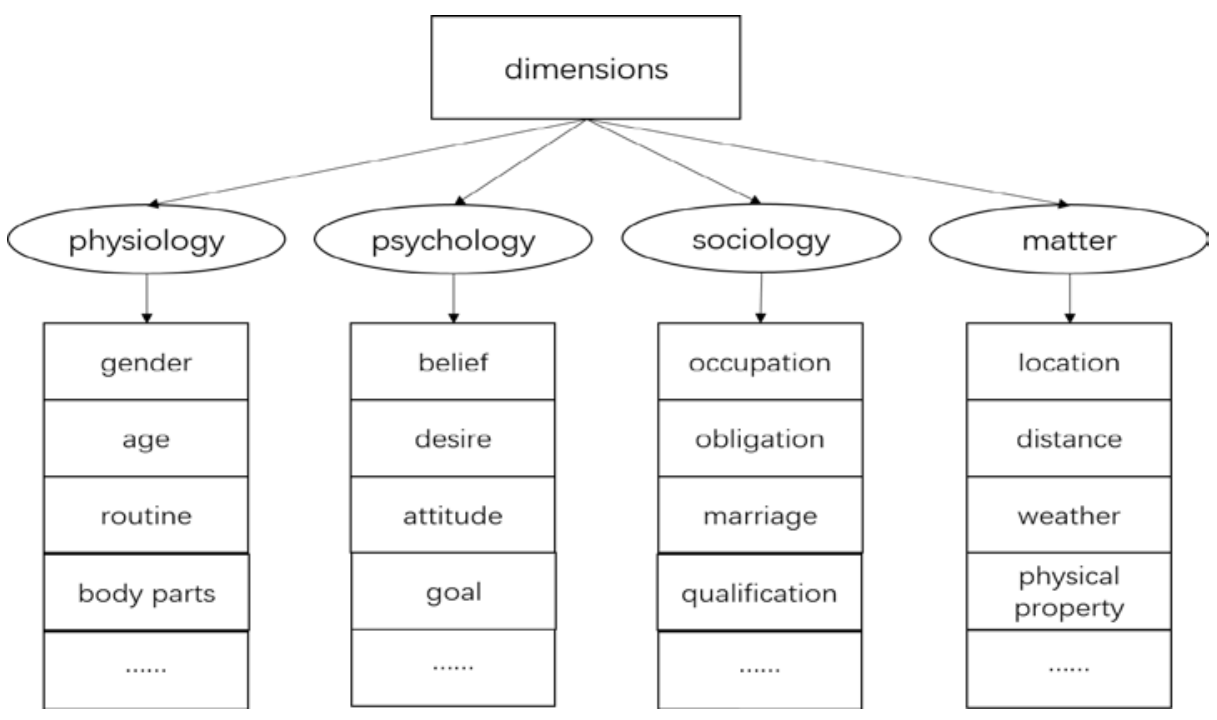

Fig. 5. Dimensions of rule expansion.

As depicted in Fig. 6, a seed rule (e.g. seed rule $_{\mathrm{j}}$ ) is situated in a certain context (e.g. Seed Context). When the dimensions of the seed rule are uncovered, knowledge engineers can use these dimensions as clues to guide them to acquire other similar rules in other contexts or in the seed context itself.

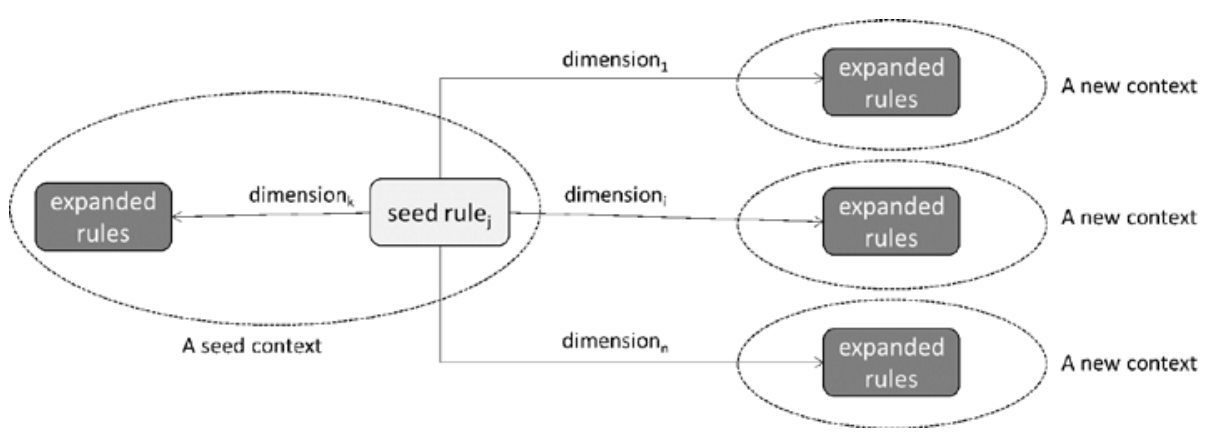

Fig. 6. Seed Rule Expansion.

First, for a given seed rule, we identify the salient dimensions of the rule. For example, the Rule 1.2 signals a gender dimension, and Rule 3.1 indicates a clothing dimension and a location dimension. We have summarized several dimensions in the 
categories of seed rules. So we can expand commonsense rules based on such dimensions as shown below.

Seed Rule: Rule1.2 (i.e. Person(p) Person(p') hasHusband(p, p')-->gender(p', male))

Expansion Dimension: Gender

\section{Expanded Rules:}

a. Person(p)\&Airline-Stewardess(a)\&hasRole(p, a)-->gender(p, female)

b. $\quad \operatorname{Person}(\mathrm{p}) \& \operatorname{Person}\left(\mathrm{p}^{\prime}\right) \&$ hasSon(p, $\left.\mathrm{p}^{\prime}\right)-->$ gender(p', male)

c. $\quad \operatorname{Person}(p) \& P e r s o n\left(p^{\prime}\right) \& g i v e ~ b i r t h$ to(p, $\left.p^{\prime}\right)-->$ gender(p, female)

Seed Rule: Rule2.1 (i.e. Person(p) Person(p') operateOn(p, p')--> $\exists$ d Physician(d) has $\operatorname{Role}(p, d))$

Expansion Dimension: Event (relation universal)

\section{Expanded Rules:}

a. $\quad$ Person(p)\&Bus(b)\&drive(p, b)--> $\exists$ d Bus-Driver(d)\&hasRole(p, d)

b. Person(p)\&Person(p')\&Restaurant(r)\&Customer(c)\&hasRole(p, c)\&orderDish(p, $\left.\mathrm{p}^{\prime}\right)-->$ hasCustomer(p', p)

c. Person(p)\&Person(p')\&Restaurant(r)\&Customer(c)\&hasRole(p, c)\&orderDish(p, $\left.\mathrm{p}^{\prime}\right)-->$ hasServer(p, p')

Seed Rule: Rule3.1 (i.e. Person(p) Person(p') Priest(p") Wedding-Dress(w) wear(p, w) \& hasRole(p', p")\&standNear(p, p')--> $\exists$ p"' Person(p'") hasBride(p"', p))

\section{Expansion Dimension: Clothing}

\section{Expanded Rules:}

a. $\quad \operatorname{Person}(\mathrm{p}) \&$ School-Uniform(u)\&wear(p, u) $\rightarrow \exists$ s Student(s)\&hasRole(p, s)

b. $\quad$ Person(p)\&Police-Unifrom(u)\&wear(p, u) $\rightarrow \exists$ r Policeperson(r)\&hasRole(p, r)

c. $\quad$ Person(p)\&Military-Uniform(u)\&wear(p, u) $\rightarrow \exists$ s Soldier(s)\&hasRole(p, s)

Seed Rule: Rule3.1 (i.e. Person(p) Person(p') Priest(p") Wedding-Dress(w) wear(p, w) \& hasRole(p', p")\&standNear(p, p') $\rightarrow \exists$ p"' Person(p"') hasBride(p"', p))

Expansion Dimension: Location

Expanded Rules:

a. $\quad$ Person(p)\&Auditorium(a)\&sitIn(p, a)--> $\exists p^{\prime}$ Audience(p')\&hasRole(p, p')

b. Person(p)\&Dock(d)\&Prison-Garb(g)\&standIn(p, d)\&wear(p, g)--> $\exists p^{\prime}$ Defendant $\left(\mathrm{p}^{\prime}\right) \&$ hasRole $\left(\mathrm{p}, \mathrm{p}^{\prime}\right)$

c. $\quad \operatorname{Person}(\mathrm{p}) \& H o s p i t a l-B e d(h) \& \operatorname{lieIn}(\mathrm{p}, \mathrm{h})-->\exists \mathrm{p}^{\prime}$ Patient(p')\&hasRole(p, $\left.\mathrm{p}^{\prime}\right)$

\section{$5 \quad$ Conclusion and Discussion}

A role-specific rule represents an assertion of some roles in a social context. In this paper, we proposed a modeling framework of social contexts, roles and relations for acquiring role-specific rules. In the framework, we introduced several new notions, 
such as context-free relation universals, context-dependent relation universals, relation universals, base roles of social contexts, and contextualization, to make our model more intuitive so that rules can be more easily uncovered. In the acquisition of role-specific rules, we first extracted such rules from Web story episodes as seed rules, and then expanded these rules using four broad categories of dimensions.

The ontological background of this work is mainly from GFO. But roles in this paper differ from GFO in the sense that: (1) there are base roles and peripheral roles in a context, but GFO does not take the peripheral roles into account, (2) we propose the relation universal hasRoleIn(Person, Role, Context) which captures more information about the structure of a role, that is, each role requires a player and a context, and (3) we introduce the notions of context-free relation universal, context-dependent relation universal and contextualization, all of which contribute to the acquisition of rolespecific rules.

One limitation of our work is that the modeling framework is more suitable for social roles, but for other types of roles such as relational roles and processual role described in GFO, a more robust framework is needed. Also, all the role-specific rules are obtained from story episodes manually which is labor-intensive and time-consuming. Moreover, role-specific rules may be improper in some more complicated cases. For example, "one person sued the other person, but the lawsuit was dismissed by the court". Then under such condition, the Rule4.1 and Rule4.2 are unreasonable. Our future work would consider these more complicated story episodes. Nevertheless, we believe that the method presented in this paper is a useful first step towards acquiring role-specific rules and further identifying roles.

One important future work is to develop a logical framework to deal with the rolespecific rules in particular, and other commonsense rules in general. In addition, exploring a semi-automatic approach to acquiring role-specific rules is another interesting future work.

\section{Acknowledgments}

This work is supported by an MOST grant (\#2017YFC1700302).

\section{References}

1. Biddle B J. Recent Developments in Role Theory[J]. Annual Review of Sociology, 1986, 12(1):67-92.

2. Chen S, Smith A M, Jhala A, et al. RoleModel: towards a formal model of dramatic roles for story generation[C]// Intelligent Narrative Technologies III Workshop. ACM, 2010:17.

3. Mori G. Social roles in hierarchical models for human activity recognition[C]// Computer Vision and Pattern Recognition. IEEE, 2012:1354-1361.

4. Boukhebouze M, Amghar Y, Benharkat A, et al. Towards Self-healing Execution of Business Processes Based on Rules[C]// Enterprise Information Systems, International Conference, Iceis 2009, Milan, Italy, May 6-10, 2009. Proceedings. DBLP, 2009:501-512. 
5. Veljko M T, Predrag R T, Zeljko M D. Expert system for fault detection and isolation of coal-shortage in thermal power plants[C]// Control and Fault-Tolerant Systems. IEEE, 2010:666-671.

6. Romanyshyn M. Rule-Based Sentiment Analysis of Ukrainian Reviews[J]. International Journal of Artificial Intelligence \& Applications, 2013, 4(4):103-111.

7. Piryani R, Gupta V, Singh V K, et al. A Linguistic Rule-Based Approach for Aspect-Level Sentiment Analysis of Movie Reviews[M]// Advances in Computer and Computational Sciences. 2017.

8. Herre H. General Formal Ontology (GFO): A Foundational Ontology for Conceptual Modelling[M]// Theory and Applications of Ontology: Computer Applications. Springer Netherlands, 2010:297-345.

9. Ramanathan V, Yao B, Li F F. Social Role Discovery in Human Events[J]. 2013, 9(4):24752482.

10. Pei M, Dong Z, Zhao M. Event recognition based-on social roles in continuous video[C]// IEEE International Conference on Multimedia and Expo. IEEE, 2013:1-6.

11. Zhang $\mathrm{J}, \mathrm{Hu} \mathrm{W}$, Yao $\mathrm{B}$, et al. Inferring social roles in long timespan video sequence[C]// IEEE International Conference on Computer Vision Workshops. IEEE, 2012:1456-1463.

12. Sapru A. Automatic social role recognition and its application in structuring multiparty interactions[J]. 2015.

13. Garg N P, Favre S, Salamin H, et al. Role recognition for meeting participants: an approach based on lexical information and social network analysis[C]// ACM International Conference on Multimedia. ACM, 2008:693-696.

14. Yaman S, Hakkani-Tür D, Tür G. Social role discovery from spoken language using dynamic Bayesian networks[C]// INTERSPEECH 2010, Conference of the International Speech Communication Association, Makuhari, Chiba, Japan, September. DBLP, 2010:2870-2873.

15. Banerjee S, Rudnicky A I. Using simple speech-based features to detect the state of a meeting and the roles of the meeting participants[C]// INTERSPEECH 2004 - Icslp, International Conference on Spoken Language Processing, Jeju Island, Korea, October. DBLP, 2004:4-10.

16. Dai Q, Carr P, Sigal L, et al. Family Member Identification from Photo Collections[C]// Applications of Computer Vision. IEEE, 2015:982-989.

17. Song Z, Wang M, Hua X S, et al. Predicting occupation via human clothing and contexts[C]// IEEE International Conference on Computer Vision. IEEE, 2011:1084-1091.

18. Morzy M. On Mining and Social Role Discovery in Internet Forums[C]// International Workshop on Social Informatics. IEEE Computer Society, 2009:74-79.

19. Doran D. On the discovery of social roles in large scale social systems[J]. Social Network Analysis \& Mining, 2015, 5(1):1-18.

20. Lv X, Jin P, Mu L, et al. Detecting User Occupations on Microblogging Platforms: An Experimental Study[M]// Web and Big Data. 2017.

21. Preotiuc-Pietro D, Lampos V, Aletras N. An analysis of the user occupational class through Twitter content[C]// Meeting of the Association for Computational Linguistics. 2015.

22. Masolo C, Vieu L, Bottazzi E, et al. Social Roles and their Descriptions[J]. 2004:267--277.

23. Jiang L P, Zhenjiang. Research on Developing Social Role Ontology of Social Groups[J]. Computer Science, 2012, 39(2):227-231.

24. Wang Ya. Research on the method of acquiring commonsense knowledge based on semantic classification [D]. Guangxi Normal University, 2015.

25. Fan J, Barker K, Porter B, et al. Representing roles and purpose[C]// International Conference on Knowledge Capture. ACM, 2001:38-43. 